д.т.н., профессор кафедры «Техносферная безопасность», ФГБОУ ВО «Иркутский государственный университет путей сообщения», e-mail: aslamovav@yandex.ru

Кузнецова Полина Андреевна, магистрант кафедры «Техносферная безопасность», ФГБОУ ВО «Иркутский государственный университет путей сообщения», e-mail: polina-kuznetsova-98@bk.ru Асламов Александр Анатольевич, к.т.н., дочент кафедры «Машины и аппарать химических производств» ФГБОУ ВО «Ангарский государственный технический университет, e-mail:aaa_mx@angtu.ru В ИРКУТСКОЙ ОБЛАСТИ И РОССИИ

Aslamova V.S., Kuznetsova P.A., Aslamov A.A.

\title{
COMPARATIVE ANALYSIS OF ROAD TRANSPORTATION INCIDENTS IN IRKUTSK REGION AND RUSSIA
}

Аннотация. B статье выполнен анализ показателей дорожно-транспортных происшествий за 2020 г. в Иркутской области и России. Выявлены основные причины реализачии ДТП. Проанализировано текущее состояние безопасности дорожного движения в рамках проекта «Безопасные и качественные автодороги». Установлено превышение фактических значений социального и транспортного рисков в 1,19 и 1,38 раз соответствующих российских показателей.

Ключевые слова: дорожно-транспортное происществие, соииальный и транспортный риски, численности раненых и погибших.

Abstract. The article analyzes the indicators of road traffic accidents for 2020 in the Irkutsk region and Russia. The main reasons for the implementation of road accidents are identified. The current state of road safety has been analyzed within the framework of the Safe and High-Quality Roads Project. An excess of the actual values of social and transport risks was established by 1.19 and 1.38 times the corresponding Russian indicators.

Keywords: road traffic accident, social and transport risks, the number of wounded and dead.

Гибель и травмирование людей, особенно несовершеннолетних, в дорожнотранспортном происшествии (ДТП) - одна из важнейших проблем всего мирового сообщества [1- 3]. Системный анализ динамики изменения показателей ДТП в Российской Федерации и Иркутской области (ИО) является основой повышения безопасности дорожного движения (БДД) и будет способствовать эффективности разрабатываемых мероприятий, направленных на обеспечение БДД и снижение числа ДТП $[2,4]$.

В таблице 1 представлены сведения Госавтоинспекции [5] о числе ДТП, случившихся в 2020 г.

Из таблицы 1 следует, что показатели ДТП в ИО в 51,6-52 раза ниже российских показателей.

В таблице 2 указана градация основных причин реализации ДТП.
Таблица 1- Показатели ДТП за 2020 г.

\begin{tabular}{|l|l|l|l|l|}
\hline $\begin{array}{l}\text { Пока- } \\
\text { затель }\end{array}$ & РФ & $\begin{array}{l}\text { АПП } \\
\Gamma, \%\end{array}$ & ИО & $\begin{array}{l}\text { АПП } \\
\Gamma, \%\end{array}$ \\
\hline $\begin{array}{l}\text { Всего } \\
\text { ДТП }\end{array}$ & 137662 & $-16,24$ & 2687 & $-18,25$ \\
\hline $\begin{array}{l}\text { По- } \\
\text { гибло }\end{array}$ & 15788 & $-7,03$ & 306 & $-15,0$ \\
\hline $\begin{array}{l}\text { Ране- } \\
\text { но }\end{array}$ & 175170 & $-16,93$ & 3369 & $-19,17$ \\
\hline
\end{tabular}

Таблица 2 - Градация основных причин реализации ДТП на автодорогах в 2020 г.

\begin{tabular}{|l|l|l|}
\hline \multicolumn{1}{|c|}{ Причина } & \multicolumn{2}{|c|}{$\%$ ДТП } \\
\cline { 2 - 3 } & РФ & ИО \\
\hline Наезд на пешехода & 24,87 & 28,62 \\
\hline Пьяный водитель & 13,50 & 17,08 \\
\hline $\begin{array}{l}\text { С участием детей } \leq 16 \\
\text { лет }\end{array}$ & 11,02 & 13,84 \\
\hline $\begin{array}{l}\text { Выезд водителя на } \\
\text { встречную полосу }\end{array}$ & 8,47 & 6,59 \\
\hline
\end{tabular}


Из таблицы 2 следует, что в ИО чаще, чем в РФ, происходят ДТП выезда по причинам:

- наезда на пешехода, что говорит о несовершенстве устройства пешеходных переходов и нарушении ПДД водителем автомобильного транспортного средства (АТС) в ИО;

- нахождения водителя в нетрезвом состоянии и участие в ДТП несовершеннолетних детей, что свидетельствует о недостатках профилактической работы с водителями, подростками и их родителями.

О состоянии БДД в рамках проекта «Безопасные и качественные дороги» (БКД) в 2020 г. можно судить по данным, представленным в таблице 3 [5].

Таблица 3 - Состояние БДД в рамках проекта

«Безопасные и качественные автодороги»

\begin{tabular}{|l|l|l|}
\hline \multicolumn{1}{|c|}{ Показатель } & \multicolumn{1}{|c|}{ РФ } & \multicolumn{1}{|c|}{ ИО } \\
\hline $\begin{array}{l}\text { Численность населе- } \\
\text { ния }\end{array}$ & 146171015 & 2375021 \\
\hline $\begin{array}{l}\text { Число АТС без при- } \\
\text { цепа }\end{array}$ & 58992696 & 824642 \\
\hline $\begin{array}{l}\text { Погибло на автодоро- } \\
\text { гах общего пользова- } \\
\text { ния }\end{array}$ & 306 \\
\hline $\begin{array}{l}\text { Фактического значе- } \\
\text { ние социального рис- } \\
\text { ка } 10,80\end{array}$ & 12,88 \\
\hline $\begin{array}{l}\text { Фактического значе- } \\
\text { ние транспортного } \\
\text { риска }\end{array}$ & 2,68 & 3,71 \\
\hline
\end{tabular}

Из таблицы 3 видно, что в ИО, численностью населения в 61,5 раз меньшей, чем в РФ, имеющая в 71,5 раз меньше АТС по сравнению с РФ, фактические значения социального (количество погибших в ДТП, на 100 тыс. населения) и транспортного (количество погибших в ДТП на 10 тыс. АТС) рисков превышают российские показатели в 1,19 и 1,38 раз соответственно.

На рисунке 1 представлена динамика показателей ДТП в 2020 г. в ИО.

Рисунок 1 демонстрирует сезонные изменения показателей ДТП в ИО. Максимальные количества ДТП и погибших наблюдается в июле и августе, минимальные - в апреле.

На рисунке 2 продемонстрирована динамика показателей ДТП в РФ в 2019 г. Из рисунка 2 видно, что максимальные количества ДТП и погибших наблюдается в августе и октябре, минимальные - в феврале.
Сезонный характер динамики показателей ДТП подтверждается также в работах $[6,7]$.

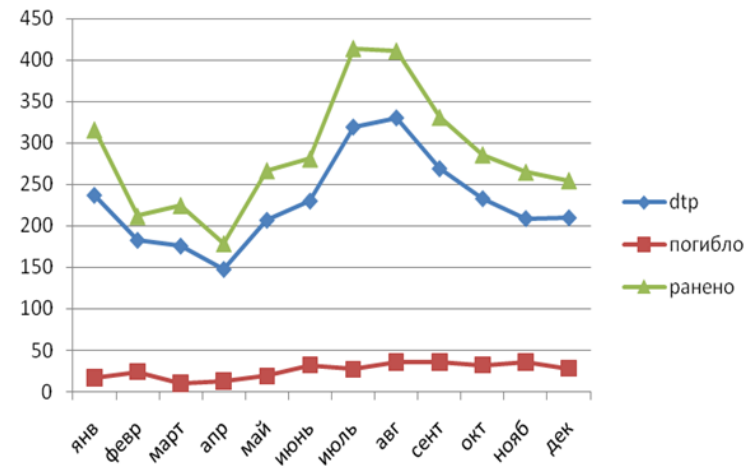

Рисунок 1 - Динамика показателей ДТП в 2020 г. в ИО

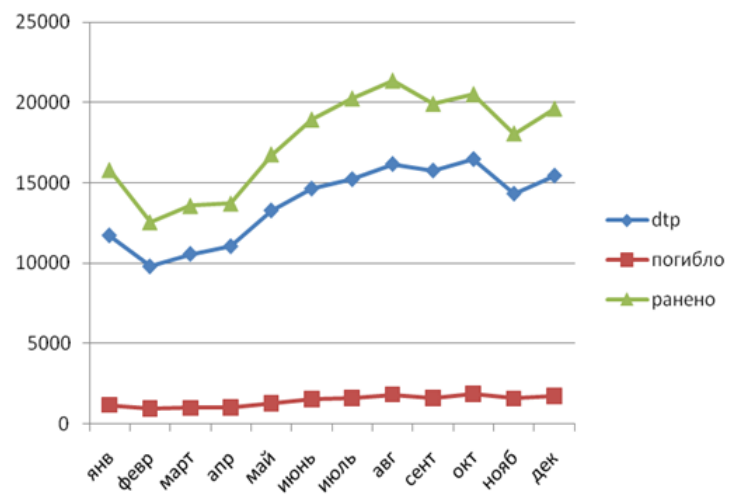

Рисунок 2 - Динамика показателей ДТП в 2019 г. в РФ

Реализацией проекта БКД на межмуниципальных и региональных автодорогах ИО занимается ОГКУ, которая совместно с Министерством строительства, дорожного хозяйства ИО разработала программу комплексного развития с целями:

- обеспечение к концу 2018 г. нормативного транспортно-эксплуатационного состояния у не менее $50 \%$ автодорог;

- уменьшение мест концентрации ДТП на $50 \%$ [8].

В 2019 г. в ИО стартовал национальный проект «Безопасные и качественные автомобильные дороги» (БКАД), целями которого являлись:

- увеличения до 38,4 \% доли автодорог регионального значения, которые соответствуют нормативным требованиям (НT);

- снижение доли автодорог регионального и федерального, значения, работающих в режиме перегрузки и их протяженности на $10 \%$; 
- уменьшение количества мест концентрации ДТП в 2 раза;

- доведение в городах ИО доли автодорог, соответствующих НТ до 85 \%.

Период реализации поставленных задач 2019-2024 годы [8]. Была проведена контрольная проверка использования бюджетных ассигнований, которые были направлены на содержание автодорог. Результаты проверки соответствия автодорог федерального, регионального (межмуниципального) значения НТ представлены в таблице 4 [9].

Установлено, что к началу 2020 г. в РФ $84,8 \%$ автодорог федерального значения соответствуют НТ, а в ИО - 70,8\%. В отношении региональных дорог ИО указанный показатель повысился по сравнению с 2017 годом лишь на 3,3 \% (в РФ на $0,9 \%$ ) и составил только 30,2 \% (в РФ 44,2\%, табл. 4).

На содержание автодорог регионального или межмуниципального значения в 2019 г. было направлено $29,6 \%$ от нормативной потребности в среднем, что не позволяет поддерживать надлежащее техническое состояние автодорог.

Анализ проверенных документов стратегического планирования показал, что целевой показатель по доведению доли автодорог межмуниципального или регионального значения ИО не достигнут за период 2017 2019 гг.

Таблица 4 - Протяженность автодорог $L$ федерального, регионального (межмуниципального) значения и $P, \%$ их соответствия

\begin{tabular}{|c|c|c|c|}
\hline \multicolumn{4}{|c|}{ HT } \\
\hline \multirow[b]{2}{*}{ Субъект } & 2017 & 2018 & 2019 \\
\hline & $\begin{array}{c}L, \text { Км } P, \\
\%\end{array}$ & $\begin{array}{c}L, \text { км } P, \\
\%\end{array}$ & $\begin{array}{c}L, \text { КМ } P, \\
\%\end{array}$ \\
\hline \multicolumn{4}{|c|}{ федеральные автодороги } \\
\hline РФ & $\begin{array}{c}53070,5 \\
77,8\end{array}$ & $\begin{array}{c}54336,6 \\
82,9\end{array}$ & $\begin{array}{c}57226,9 \\
84,8\end{array}$ \\
\hline ИО & $\begin{array}{c}1664,4 \\
65,0\end{array}$ & $\begin{array}{c}1657,2 \\
57,5\end{array}$ & $\begin{array}{c}1628,5 \\
70,8\end{array}$ \\
\hline \multicolumn{4}{|c|}{ региональные автодороги } \\
\hline РФ & $\begin{array}{c}510969,9 \\
43,1\end{array}$ & $\begin{array}{c}510421,1 \\
42,4\end{array}$ & $\begin{array}{c}508201,3 \\
44,2\end{array}$ \\
\hline ИО & $\begin{array}{c}12037,7 \\
26,9\end{array}$ & $\begin{array}{c}12011,8 \\
28,3\end{array}$ & $\begin{array}{c}12011,8 \\
30,2\end{array}$ \\
\hline
\end{tabular}

Контрольно-счетной палатой ИО было установлено отсутствие разработанных планов работ по содержанию региональных автодорог.

\section{СПИСОК ЛИТЕРАТУРЫ}

1. Аземша С. А., Карасевич С. Н. Учет динамики аварийности при разработке мероприятий по повышению безопасности дорожного движения // Организация и безопасность дорожного движения: материалы XII Национальной научно-практической конференции с международным участием (14 марта 2019 г.). В 2-х томах. Т. 2. / отв. ред. Д. А. Захаров. - Тюмень: ТИУ, 2019. - С. 8-14.

2. Асламова В.С. Системный анализ травматизма с участием детей на российских автомобильных дорогах / В. С. Асламова, А. А. Минко, А. А. Асламов, Е. А. Асламова // Современные технологии. Системный анализ. Моделирование. - 2021. - № 2 (70). - С. 109-113.

3. Хабибуллин Д. Р., Ильдарханов Р. Ф. Современные проблемы безопасности дорожного движения // Организация и безопасность дорожного движения: материалы XII Национальной научно-практической конференции с международным участием (14 марта 2019 г.). В 2-х томах. Т. 2. / отв. ред. Д. А. Захаров. - Тюмень: ТИУ, 2019. С. 101-108.
4. Бессараб А. В. Автомобильный транспорт и проблема повышения безопасности дорожного движения // Наука и техника. № 4. 2013. С. 71-76.

5. Сведения о показателях состояния безопасности дорожного движения: сайт Госавтоинспекции. URL: http://stat.gibdd.ru/ (дата обращения 07.10.2021).

6. Паршина К. С. Снижение риска ДТП на основе анализа аварийности по месяцам года / К. С. Паршина ; науч. рук. Е. В. Печатнова // Экология и безопасность в техносфеpe: современные проблемы и пути решения : сборник трудов Всероссийской научнопрактической конференции молодых ученых, аспирантов и студентов, г. Юрга, 23-25 ноября 2017 г. - Томск : Изд-во ТПУ, 2017. - С. 623-625.

7. Анализ детского дорожнотранспортного травматизма МУ МВД России «Иркутское» за 12 месяцев 2019 года.pdf.

8. Национальный проект «Безопасные и качественные дороги» 2019-2024. Опыт реализации приоритетного проекта «Безопасные 